\title{
Organizational Semiotics and Participatory Design to Requirements Elicitation - A Case Study
}

\author{
Flávia Linhalis Arantes ${ }^{1}$ \\ ${ }^{1}$ Núcleo de Informática Aplicada à Educação (NIED) \\ Universidade Estadual de Campinas (UNICAMP) \\ Campinas - SP - Brazil \\ farantes@unicamp.br
}

\begin{abstract}
It is already agreed that requirements have a critical impact on the quality and users satisfaction of the resulting software. In this work, web information systems are reviewed from the perspective of organizational semiotics as being part of an organization, which comprises work practices, rules and views of the same system by different stakeholders. This paper presents a case study, where artifacts of the organizational semiotics are exploited in a collaborative and participatory way to requirements elicitation of a web information system.
\end{abstract}

\section{Introduction}

Requirements Engineering (RE) is the process of discovering the purpose for which a software system was intended by identifying stakeholders and their needs, and documenting these in a form that is suitable to analysis, communication, and implementation [Nuseibeh and Easterbrook 2000]. Stakeholders may be numerous and their goals may vary and conflict, depending on the perspectives of their work environment and the tasks they wish to accomplish. Baranauskas and colleagues [Baranauskas et al. 2005] propose a semiotic-based method for stakeholders identification and requirements elicitation considering social, political, cultural and ethical issues involved in understanding the problem in the process of RE. Their approach is based on Organizational Semiotics (OS) [Liu 2000], which studies organizations using concepts and methods from Semiotics [Stamper 1973].

If we think about an information system as being part of an organization, which comprises work practices, rules and views of the same system by different stakeholders; it is natural to conclude about the advantages of involving users in the information system development.

The Participatory Design (PD) proposes users active participation in several moments of a technological product development life cycle [Ehn 1992]. In PD, the ultimate users of the software make effective contributions that reflect their own perspectives and needs, somewhere in the design and development life cycle of the software. Active participation is more than being used as mere data sources by responding to questionnaires or being observed while using the software. User participation is no longer restricted to designing per se; it is valuable in activities throughout the entire software life cycle [Muller et al. 1997].

In this work, artifacts of the OS were used in a collaborative and participatory way to requirements elicitation of a multidisciplinary web site. Results of the case study 
allowed us to observe the contribution of OS to requirements elicitation when we think about the system as being part of a social organization.

This paper is organized as follows: section 2 gives a brief background about organizational semiotics and its artifacts that can be applied to requirements elicitation. Section 3 presents web information systems from the perspective of OS. Section 4 presents a web site case study, showing how participatory practices and OS artifacts were applied to requirements elicitation. Finally, section 5 concludes the paper with some remarks on future work.

\section{Organization Semiotics Artifacts to Requirements Elicitation}

Organizational semiotics is the study of organizations using the concepts and methods of the semiotics. This study is based on the fundamental observation that all organized behavior is affected through the communication and interpretation of signs by people, individually or in groups. The aims of OS study are to find new and insightful ways of analysing, describing and explaining organizations [Liu 2000]. In this context, the role of the system analyst is to help users to articulate their problems, to discover their information requirements, and to develop a systematic solution to reach the technical information system.

Artifacts and methods of OS have been reviewed and used to several tasks related to requirements elicitation, such as stakeholders identification with their related responsibilities, better understanding of different information aspects, identification of problems, questions, solutions and ideas of the information system in focus [Baranauskas et al. 2005, Bonacin et al. 2006, Simoni et al. 2007]. In the following subsections, some OS artifacts that can be used to support requirements elicitation are described.

\subsection{OS Onion and Stakeholders Analysis}

In a semiotic perspective, different layers of meaning must be considered in the information system analysis and software design. Figure 1 represents the relation between the different layers of an information system [Liu 2000].

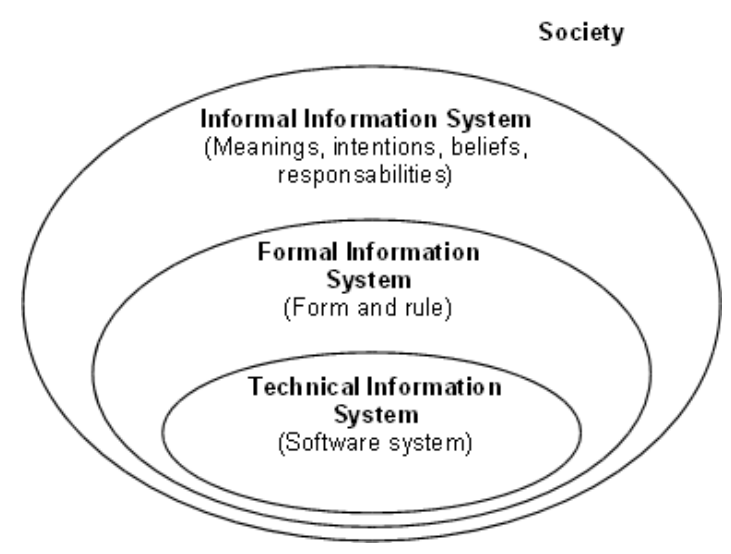

Figure 1. Organizational Semiotics Onion.

At an informal level there is a sub-culture in which meanings are established, intentions are understood, beliefs are formed and commitments with responsibilities are 
made. At a formal level, form and rule replace meaning and intention. At a technical level, part of the formal system is automated by a computer-based system. The informal level embodies the formal that, by its turn, embodies the technical level, meaning that changes in some level have impact in other levels.

The OS layers structure (known as OS onion) has been used to help stakeholders analysis before the beginning of a new information system development. In this activity, the problem in focus, or design problem, should be clarified and the stakeholders have to be identified and organized in the informal, formal and technical layers [Baranauskas et al. 2005, Bonacin et al. 2006]. Figure 2 illustrates the artifact adapted to guide the problem clarification and the stakeholders analysis in a semiotic perspective.

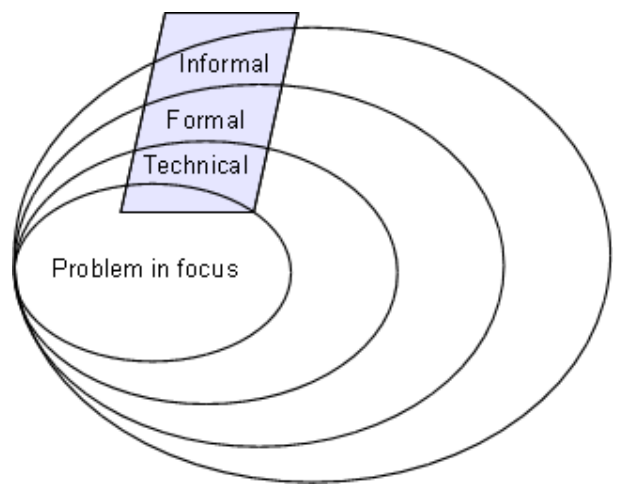

Figure 2. Organizational Semiotics onion adapted to problem clarification and stakeholders analysis.

\subsection{Semiotic Ladder}

The semiotic ladder (Figure 3) is a structure that organizes the different levels of information. Each level deals with a limited set of questions related to signs. As so, it favors/supports a semiotic view of information systems requirements considering the information different aspects. The semiotic ladder organization expresses the idea of constructing the properties of a system in each level from the ones identified in lower levels, until reaching the social level, where the signs represent their valuable contributions [Stamper 2001].

The semiotic ladder has been used as an artifact to support information system analysis from requirements elicitation to interface design [Baranauskas et al. 2005, Schimiguel 2006, Chebabi 2005].

\subsection{Evaluation Frame}

Evaluation frames are artifacts constructed to analyze the current system (if there is one) and understand what is expected from the new system [Simoni 2003]. The evaluation frame has been used to organize the interests, ideas, questions and problems identified by stakeholders during requirements elicitation participatory practices [Baranauskas et al. 2005, Bonacin et al. 2006, Simoni et al. 2007]. Figure 4 shows a structure that can be adopted to the evaluation frame. 


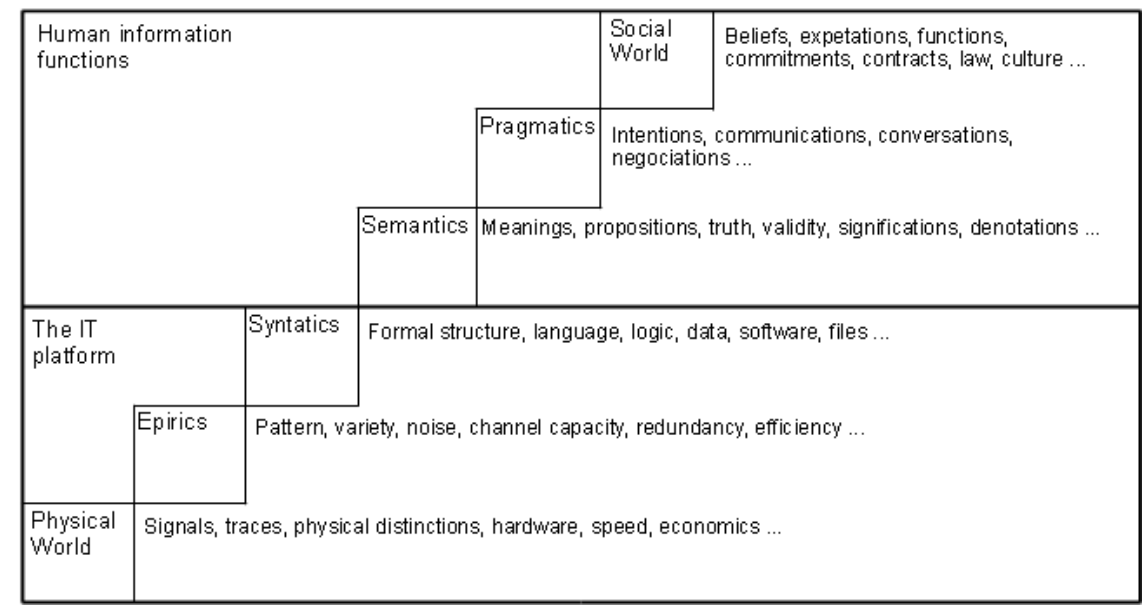

Figure 3. The Semiotic Ladder [Liu 2000].

\begin{tabular}{|l|l|l|}
\hline \multicolumn{1}{|c|}{ Stakeholders } & Questions / Problems & Ideas / Solutions \\
\hline Informal & & \\
\hline Formal & & \\
\hline Technical & & \\
& & \\
\hline
\end{tabular}

Figure 4. Evaluation frame structure [Simoni 2003].

\section{An Organizational Semiotics Perspective to Web Information Systems}

According to Melo [Melo 2007], in an Organizational Semiotics perspective, if we consider the web as an example of technical information system, then the global society could be seen as the informal information system. The norms to rule their actions (i.e. development, maintenance and use of the technical systems) would be part of the formal information system.

If we take a web information system in particular (an institutional portal for example), the informal layer would be represented by the institution that owns the portal, and by all social groups that are interested on its activities. In the formal layer, the focus would be in the norms, for example, local and national legislation, strategic planning, internal regulation, work procedures, contracts, privacy policies, and so on.

The semiotic ladder can support information systems analysis to web information systems [Melo 2007]:

- Physics: hardware infra-structure, such as, servers, transmission channels, client computers, input and output devices, etc.

- Empirics: bandwidth, network protocols, data transmission, access efficiency, throughput, etc.

- Syntactics: relates to development frameworks, web programming languages, W3C recommendations, file systems, documentation, browsers, and so on. 
- Semantics: this layer can be understood according to different point of views. For example, (1) who are the users, their needs and interests; (2) the meaning assigned by the designers to interface elements; (3) the meaning that users construct to the system interfaces; and so on.

- Pragmatics: relates to established communication, adopted work procedures, users intentions, content producers intentions, etc.

- Social World: relates to values, legislation, expectations, cultural influences, beliefs, established compromises, and so on.

This brief analysis provides support to the fact that web information systems design should be understood as a wide perspective, that treats technical aspects as well as human values aspects, compromises and intentions. This aspects should be considered to information systems requirements elicitation, as well as interface design activities, evaluation and maintenance.

\section{A Multidisciplinary Web Site Case Study}

The NIED (Nucleus of Informatics Applied to Education) web site is the object of this case study. NIED is a multidisciplinary nucleus, which aggregates researchers from several areas, such as education, pedagogy, computing, arts and engineering; with focus on informatics in education research. Its web site is expected to meet this interdisciplinary nature and to highlight the nucleus projects and advances.

NIED's current web site ${ }^{1}$ was contracted as a third party service. The lack of users participation during the design process leaded to dissatisfaction and frustration when the web site was delivered.

The site is now under a (re)design process. Participatory practices [Muller et al. 1997] are being considered and supported by organizational semiotics [Liu 2000] artifacts. In this study case, the requirements elicitation phase is described. The main contribution of this paper is to show a web information system case study that joins participatory practices and OS artifacts with focus on requirements elicitation.

In the following subsections, stakeholders identification, requirements elicitation and validation phases applied to NIED's web site are described, together with the OS artifacts used to support each activity.

\subsection{Stakeholders Identification}

The first step to requirements elicitation was to clarify the design problem and to identify the users (or stakeholders) to take part in the participatory practices. In order to perform this two activities, a brief participatory workshop was conducted with NIED's board members (researchers, teachers, coordination and administrative staff) ${ }^{2}$.

The OS onion artifact, presented in Figure 2, was used to support this activity. Firstly, the design problem (or problem in focus) was exposed by the workshop mediator as being "the development of a web site to meet NIED's interdisciplinary nature and to highlight the nucleus projects and advances". The workshop mediator explained the OS

\footnotetext{
${ }^{1}$ http://www.nied.unicamp.br/. Accessed in January, 24th, 2011.

${ }^{2}$ The first workshop happened at October 1st, 2010; and lasted about 1 hour.
} 
onion artifact to the participants. Through a brainstorming, they helped to identify stakeholders and to classify them in informal, formal and technical layers. Figure 5 summarizes this activity results.

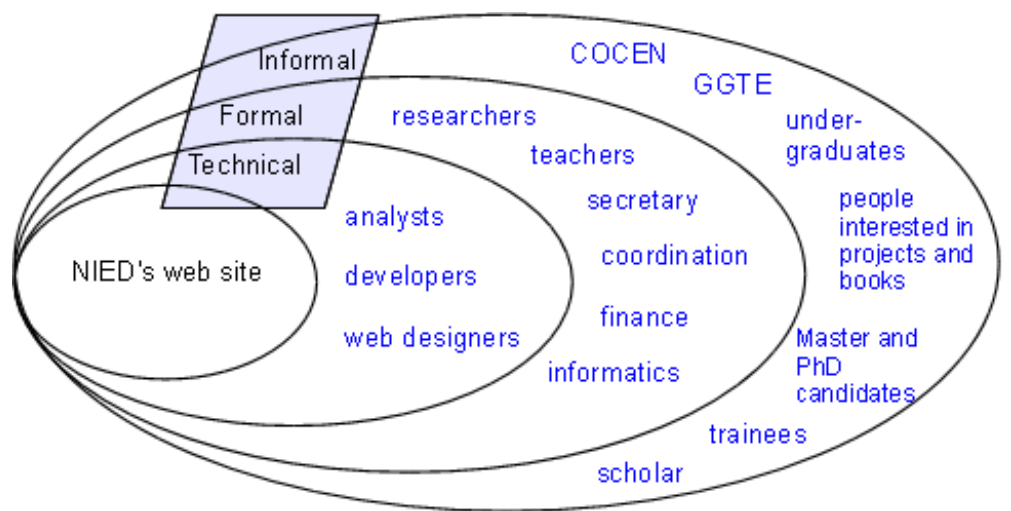

Figure 5. OS onion applied to NIED's web site stakeholders identification.

In the inner layer, the problem in focus (NIED's web site) is represented. In the technical layer, part of the formal system is automated - so technical stakeholders were identified (developers, analysts and web designers). In the formal layer, norms, work procedures and internal rules are established. At this level, people who rule work procedures at NIED were identified - these are coordination, researchers, teachers, secretary, finance staff and informatics staff. In the informal layer, the NIED itself and other social groups interested on its activities were identified - undergraduates, master and $\mathrm{PhD}$ candidates, trainees, scholar, external community interested in books or projects developed by NIED, COCEN (Interdisciplinary Nucleus and Research Centers Coordination) and GGTE (Educational Technologies Manager Group).

\subsection{NIED's Web Site Requirements Elicitation}

Once the stakeholders were identified, another participatory workshop supported by organization semiotics artifacts were conducted with focus on requirements elicitation. At least one person of the following stakeholders groups took part in the workshop ${ }^{3}$ : developers, analysts, web designers, researchers, secretary, informatics, undergraduates, $\mathrm{PhD}$ candidates, scholars, trainees, COCEN and GGTE.

In the second workshop, the mediator firstly revisited the OS onion artifact, filled in the first workshop. The design problem were also reviewed, as some participants were not present in the first workshop because they were identified as stakeholders in that occasion.

The workshop mediator also presented other two artifacts that would be used to requirements elicitation: the evaluation frame (Figure 4) and the semiotic ladder (Figure $3)$.

With support of the evaluation frame artifact, the mediator asked the participants to identify questions, problems, ideas and solutions for the site and write them in post-its. The stakeholders of each layer (informal, formal and technical) were all together in this

\footnotetext{
${ }^{3}$ The second workshop happened at October 22th, 2010; and lasted about 3 hours.
} 
activity. After writing in the post-its, each one exposed to the group his/her questions and ideas to NIED's site, according to the vision they had of the system. In order to organize and register the users contributions, an evaluation frame poster was filled with the post-its by the mediator. Figure 6(a) shows the workshop participants, (b) the mediator filling the evaluation frame poster and, (c) the completed artifact in the end of the workshop.

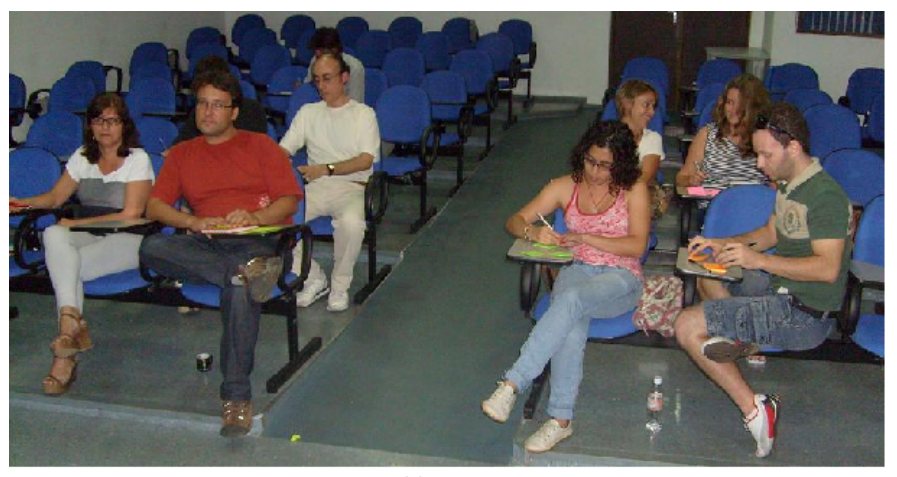

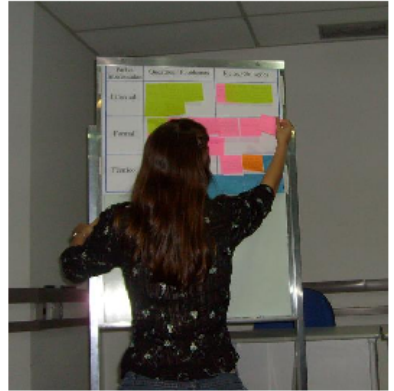

(b)

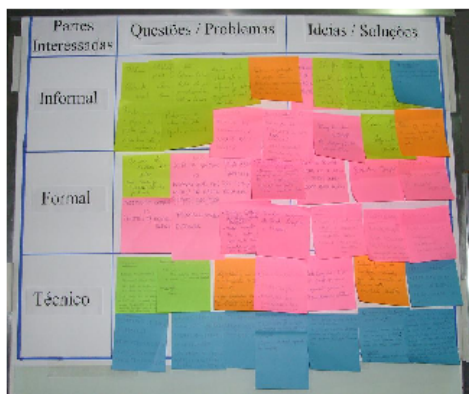

(c)

Figure 6. (a) Stakeholders in the participatory workshop; (b) Mediator filling the evaluation frame, an OS artifact adopted to support the participatory requirements elicitation activity; (c) Evaluation frame completed.

User participation in different semiotic levels led to heterogeneous ideas of the system. When these ideas were exposed to the group, they were enriched in a participatory manner. Tables 1, 2 and 3 summarize the evaluation frame main results, showing contributions to the informal, formal and technical layers, respectively. For each question/problem a solution/idea was proposed.

The semiotic ladder (Figure 3) was also adopted to support requirements elicitation (mainly non-functional requirements). With this artifact was possible to reorganize some human aspects of information related to social world (compromises), pragmatics (intentions) and semantics (meanings).

Some compromises registered in the semiotic ladder were related to information security and availability, compliance with legislation (Unicamp norms, W3C recommendations, accessibility laws), different browsers compatibility, and keeping the site up to date.

The intentions observed about the stakeholders needs and interests were related to ease the content management, to improve the site visibility (access rate), to improve NIED's projects visibility, and to make the site more intuitive and dynamic. 
Table 1. Evaluation frame results for informal layer.

\begin{tabular}{|c|c|}
\hline Questions and Problems & Ideas and Solutions \\
\hline $\begin{array}{l}\text { 1) The projects in the site are usually out- } \\
\text { dated. }\end{array}$ & $\begin{array}{l}\text { 1) Someone have to cover the project's } \\
\text { upgrade. }\end{array}$ \\
\hline $\begin{array}{l}\text { 2) Tell the story of NIED, including } \\
\text { projects and people. }\end{array}$ & $\begin{array}{l}\text { 2) Make a time line, indicating projects, } \\
\text { participants, and important events. }\end{array}$ \\
\hline $\begin{array}{l}\text { 3) More integration of NIED's commu- } \\
\text { nity (students, researchers, teachers, ...). } \\
\text { 4) NIED's web site internationalization }\end{array}$ & $\begin{array}{l}\text { 3) Create NIED's community as a social } \\
\text { network and access it from the site. } \\
\text { 4) Use automatic translation (like google } \\
\text { translate) }\end{array}$ \\
\hline $\begin{array}{l}\text { 5) In the current site, it is difficult to find } \\
\text { NIED's address and location. }\end{array}$ & 5) Put these information in the main page. \\
\hline 6) Make the site more interesting. & $\begin{array}{l}\text { 6) Increase the visibility of projects with } \\
\text { multimedia. }\end{array}$ \\
\hline 7) Make the site more interactive & 7) Use blogs. \\
\hline
\end{tabular}

Table 2. Evaluation frame results for formal layer.

\begin{tabular}{|l|l|}
\hline Questions and Problems & Ideas and Solutions \\
\hline 1) Enable users to buy books. & 1) Implement electronic commerce. \\
2) Lack of administrative resources in the & 2) Create an Intranet to administrative \\
current site. & subjects. \\
3) Problems with meeting schedule in & 3) Implement scheduling to NIED's meet- \\
NIED's physical space. & ing room. \\
4) Customize some common areas in the & 4) Make a minimum template to projects \\
site. & and personal home pages. \\
5) Problems to keep private areas up to & 5) Design simpler administration inter- \\
date. & $\begin{array}{l}\text { faces to encourage users to update their } \\
\text { areas. }\end{array}$ \\
6) More integration with NIED's research & 6) Allow access to projects' web pages \\
projects. & according to user permissions. \\
7) More integration with NIED's research & 7) Allow community contributions re- \\
area. & lated to projects research focus. \\
8) It is difficult to keep the site up to date & 8) Decentralize - allow multiple users to \\
with events and news. & to edit this area. \\
9) It is difficult to keep productions & 9) Decentralize - each researcher respon- \\
(books, memos, papers) up to date. & sible for his/her projects. \\
10) Ease access to NIED's books. & 10) Make a digital library. \\
\hline
\end{tabular}

The observations about meaning focused on usability, accessibility, internationalization, understandable interfaces, conceptualization of the interface by the stakeholders, and the use of time line metaphor.

After the workshop, the semiotic ladder were reviewed and updated mainly with infrastructure aspects. Its results are presented in Figure 7.

Besides requirements elicitation, the participatory workshop supported by organi- 
Table 3. Evaluation frame results for technical layer.

\begin{tabular}{|l|l|}
\hline Questions and Problems & Ideas and Solutions \\
\hline
\end{tabular}

1) Make the site accessible (at least to visual impaired users).

2) See NIED's news without entering the site.

3) It is difficult to find information in the current site.

4) Access the site using other platforms.

1) Adopt W3C WAI (Web Accessibility Initiative).

2) Use RSS and/or social networks.

3) Make the site map.

4) Consider mobile devices (such as PDAs).

\begin{tabular}{|c|c|c|c|c|c|c|}
\hline & & & \multirow[b]{3}{*}{$\begin{array}{c}\text { Semantics } \\
\text { Meanings ... }\end{array}$} & \multicolumn{2}{|c|}{$\begin{array}{r}\text { Social } \\
\text { World } \\
\text { Compromises } \ldots\end{array}$} & $\begin{array}{l}\text { - Keep the site up to date } \\
\text { - Guarantee information security } \\
\text { and availability } \\
\text { - Compliance with legislation } \\
\text { - Browsers compatibility }\end{array}$ \\
\hline & & & & $\begin{array}{c}\text { Pragmatics } \\
\text { Intentions } \ldots\end{array}$ & \multicolumn{2}{|c|}{$\begin{array}{l}\text { - Easy content management } \\
\text { - Improve the site visibility (access rate) } \\
\text { - Improve NIED's projects visibility } \\
\text { - Make the site more intuitive and dynamic }\end{array}$} \\
\hline & & & & \multicolumn{3}{|c|}{$\begin{array}{l}\text { - Usability, accessibility } \\
\text { - Understandable interfaces } \\
\text { - Stakeholders conceptualization of the interface } \\
\text { - Timeline metaphor } \\
\text { - Internationalization }\end{array}$} \\
\hline & \multicolumn{2}{|c|}{$\begin{array}{r}\text { Syntactics } \\
\text { Languages, softwares, } \\
\text { formats } \ldots\end{array}$} & \multicolumn{4}{|c|}{$\begin{array}{l}\text { - Free and accessible technology } \\
\text { - XHTML, CSS, RSS } \\
\text { - CMS Drupal, PHP, Apache server }\end{array}$} \\
\hline & $\begin{array}{r}\text { Empirics } \\
\text { performance, } \\
\text { capacity... }\end{array}$ & \multicolumn{5}{|c|}{$\begin{array}{l}\text { - Performance (response and access time) } \\
\text { - Bandwidth } \\
\text { - Backup frequency }\end{array}$} \\
\hline $\begin{array}{r}\text { Physical } \\
\text { machines, } \\
\text { nfraestructure... }\end{array}$ & \multicolumn{6}{|c|}{$\begin{array}{l}\text { - Unicamp network } \\
\text { - NIED's server } \\
\text { - No break } \\
\text { - Backup disc }\end{array}$} \\
\hline
\end{tabular}

Figure 7. Semiotic ladder artifact applied to NIED's web site.

zational semiotics artifacts served to outline a common view for the aspects involved in NIED's site (re)design, according to heterogeneous stakeholders impressions. Its results relate mainly to accessibility, maintainability, dissemination of projects, content decentralization and compromises with upgrades of news and projects.

The workshop results were discussed later with the technical team and the coordination, aiming to complement and contribute to requirements elicitation that should be further validated by the stakeholders. 


\subsection{Requirements Validation}

The third participatory workshop was organized with the stakeholders for the purpose of delimiting the scope of the redesign ${ }^{4}$. The requirements were classified into functional and non-functional, as suggested by Sommerville [Sommerville 2003].

Before the second workshop, the following requirements were reformulated and validated by the coordination and technical team:

- Electronic commerce does not fit in NIED's educational nature.

- There is already an Intranet for some administrative matters. There is no need to create another.

- Community contributions to projects also imply in responsibilities with posted content.

- Decentralize content publishing and management whenever possible.

- The digital library and mobile devices access were considered interesting requirements, but due to the limited development team, they will not be considered for now.

Firstly, the semiotic ladder and the evaluation frame developed in the last workshop were revisited. Afterward, the functional and non-functional requirements were presented and considered one by one.

The most prioritized functional requirements related to other ways to spread news (RSS and social networks), to ease the access to NIED's books and projects, to customize projects and staff pages, to decentralize content management, and to represent NIED's community.

The non-functional requirements highlighted by the stakeholders are related to accessibility, usability, metaphor to content organization (time line view), visual identity, updated content, and emphasis on NIED's projects.

\subsection{Discussion}

It is an agreement that a software cannot function in isolation from the organizational and social context in which it is embedded. According to Baranauskas et al [Baranauskas et al. 2005], the Organizational Semiotics methods allow to encompass a system level view, involving the team into considerations about the formal and informal levels; instead of emphasizing the behavior of the software system as usually proposed by traditional methodologies.

As a multi-disciplinary and human-centered process, the participatory approach facilitated discussion among the stakeholders during the workshops, leading to a better understanding of the context and social implications of the system. Communication between the stakeholders was facilitated by the Organizational Semiotics artifacts, which allowed meaning negotiation and context understanding by a shared representation of the data being captured, analyzed, and discussed.

Requirement Engineering is concerned with interpreting and understanding stakeholder terminology, concepts, viewpoints and goals. With participatory workshops the terminology can be naturally originated from the stakeholders themselves, who express their ideas in post-its, and discuss their viewpoints and goals with others in the group.

\footnotetext{
${ }^{4}$ The third workshop happened at November 12th, 2010; and lasted about 2 hours.
} 


\section{Conclusion and Future Work}

Inefficient requirements elicitation has been one of the causes of delivered systems that do not meet their customers requirements; like happened with NIED's current web site when it was delivered. Moreover, requirements engineering is often regarded as a timeconsuming and bureaucratic process. In this paper, a study case that adopted a participatory approach supported by organization semiotics artifacts to requirements elicitation was presented. OS provided artifacts for the participatory workshops to guide stakeholders identification and requirements elicitation.

Results achieved in this case study, as well as in other application of the theoretical framework of Organizational Semiotics to information system design [Bonacin et al. 2004, Bonacin et al. 2006, Simoni et al. 2007], encourage its use to bridge the gap between requirements elicitation and more formal specification and analysis techniques. As a future work, participatory practices supported by OS are going to be exploited with study cases in other phases of web information systems engineering.

\section{Acknowledgments}

Thanks to users that took part in the participatory workshops.

Thanks to FAEPEX/UNICAMP and AFPU/UNICAMP for funding the project presentation.

\section{References}

Baranauskas, M. C. C., Schimiguel, J., Simoni, C. A. C., and Medeiros, C. B. (2005). Guiding the process of requirements elicitation with a semiotic approach. In Inc., L. E. A., editor, Proceedings of the 11th International Conference on Human-Computer Interaction, volume 3, pages 100-110, Las Vegas, USA.

Bonacin, R., Baranauskas, M., and Liu, K. (2004). From ontologu charts to class diagrams: semantic analysis aiding systems design. In Proceedings of 6th ICEIS, Porto, Portugal.

Bonacin, R., Simoni, C. A. C., Melo, A. M., and Baranauskas, M. C. C. (2006). Organisational semiotics: guiding a service-oriented architecture for e-government. In Baranauskas, M. C. C. and Liu, K., editors, Proceedings of the First International Conference on Organisational Semiotics, pages 47-58, Campinas, SP, Brazil.

Chebabi, R. Z. (2005). Modelagem e proposta de sistema para mediar processos de comunicação em organizações enxutas. Master's thesis, Institute of Computing, Unicamp, Campinas, Brazil.

Ehn, P. (1992). Usability: Turning technologies into tools, chapter Scandinavian design: on participation and skill, pages 96-132. Oxford University Press, Inc., New York, NY, USA.

Liu, K. (2000). Semiotics in Information Systems Engineering. Cambridge University Press, Cambridge. 
Melo, A. M. (2007). Design Inclusivo de Sistemas de Informação na Web. PhD thesis, Institute of Computing, Unicamp.

Muller, M. J., Haslwanter, J. H., and Dayton, T. (1997). Handbook of Human-Computer Interaction, chapter Participatory Practices in the Software Lifecycle, pages 255-297. Elsevier.

Nuseibeh, B. and Easterbrook, S. M. (2000). Requirements engineering: a roadmap. In ICSE - Future of SE Track, pages 35-46.

Schimiguel, J. (2006). Um framework para a avaliação de interfaces de aplicações SIG web no domínio agrícola. $\mathrm{PhD}$ thesis, Institute of Computing, Unicamp, Campinas, Brazil.

Simoni, C. A. C. (2003). A prática de desenvolvimento de software e a abordagem da semiótica organizacional. Master's thesis, Institute of Computing, Unicamp.

Simoni, C. A. C., Melo, A. M., and Baranauskas, M. C. C. (2007). Project Management and Risks Management in Complex Projects, chapter Towards a social-based process for information system development: a case study, pages 177-192. Springer.

Sommerville, I. (2003). Software Engineering. 6th edition.

Stamper, R. (1973). Information in business and administrative systems. John Wiley \& Sons, Inc., New York, NY, USA.

Stamper, R. K. (2001). Information, organization and technology: studies in Organisational Semiotics, chapter Organisational Semitics: information without the computer?, pages 115-171. Kluwer Academic Publishers, Bostom. 